\title{
DCE-MRI assessment of the effect of vandetanib on tumor vasculature in patients with advanced colorectal cancer and liver metastases: a randomized phase I study
}

Journal of Angiogenesis Research 1:5 I DOI: 10.1186/2040-2384-1-5 I C Li et al.; licensee Publiverse Online S.R.L. 2009

Received: 10 Jul 2009 | Accepted: 21 Jul 2009 | Published: 21 Jul 2009

Mross Klaus ${ }^{@}$, Fasol Ulrike, Frost Annette, Benkelmann Robin, Kuhlmann Jan, Büchert Martin, Unger Clemens, Blum Hubert, Hennig Jürgen, Milenkova Tsveta P, Tessier Jean, Krebs Annetta D, Ryan Anderson J, Fischer Richard

${ }^{+}$Contributed equally ${ }^{@}$ Corresponding author

\begin{abstract}
Background

Vandetanib is a once-daily oral inhibitor of VEGFR, EGFR and RET signaling pathways. In patients with advanced colorectal cancer and liver metastases, the effect of vandetanib on tumor vasculature was assessed using dynamic contrast-enhanced magnetic resonance imaging (DCE-MRI).
\end{abstract}

\section{Methods}

Eligible patients received vandetanib 100 or $300 \mathrm{mg} /$ day. DCE-MRI (iAUC ${ }_{60}$ and $\mathrm{K}^{\text {trans }}$ ) was used to quantify the primary endpoints of tumor perfusion and vascular permeability. An exploratory assessment of tumor oxygenation was performed using MRI/T2*. All MRI parameters were measured at baseline (twice) and on days 2, 8, 29 and 57.

\section{Results}

Twenty-two patients received vandetanib ( $n=10,100 \mathrm{mg} ; n=12,300 \mathrm{mg}$ ). Baseline measurements of iAUC ${ }_{60}$ and K trans were reproducible, with low intrapatient coefficients of variation (11\% and $24 \%$, respectively). Estimates of mean $\%$ changes from baseline were $-3.4 \%(100 \mathrm{mg})$ and $-4.6 \%(300 \mathrm{mg})$ for iAUC ${ }_{60}$, and $-4.6 \%(100 \mathrm{mg})$ and $-2.7 \%(300$ $\mathrm{mg}$ ) for $\mathrm{K}^{\text {trans }}$; these changes were not significantly different between doses. The exploratory $\mathrm{T} 2 *$ measurement showed a significant increase at $300 \mathrm{mg}$ versus $100 \mathrm{mg}(P=0.006)$. Both doses of vandetanib were generally well tolerated; common toxicities were fatigue, rash and diarrhea (majority CTC grade 1 or 2 ). The pharmacokinetic profile of vandetanib was similar to that observed previously. There were no RECIST-defined objective responses; five patients experienced stable disease $\geq 8$ weeks.

\section{Conclusion}

In this study in patients with advanced colorectal cancer, vandetanib did not modulate gadolinium uptake in tumor vasculature and tissue measured by the DCE-MRI parameters iAUC ${ }_{60}$ and $\mathrm{K}^{\text {trans }}$.

Trial registration

NCT00496509(ClinicalTrials.gov); D4200C00050 (AstraZeneca)

\section{Background}

Vascular endothelial growth factor (VEGF) has a pivotal role in tumor angiogenesis, which is required for the growth of most solid tumors and the formation of metastases. The VEGF signaling pathway is a validated therapeutic target in several solid tumors, including advanced colorectal cancer [ 1], non-small-cell lung cancer [2] and renal cell carcinoma $[3,4]$. 
Dynamic contrast-enhanced magnetic resonance imaging (DCE-MRI) is a non-invasive functional imaging technique that permits indirect measurement of tumor hemodynamics. It may therefore be suitable for monitoring the effects of VEGF signaling inhibitors on tumor vasculature. DCE-MRI utilizes a low molecular weight paramagnetic contrast agent such as gadolinium-DTPA, which readily diffuses from the blood to the extravascular extracellular space. By acquiring a set of rapid MR images, the time course of the change in T1 relaxation time induced by the contrast agent may be followed. Contrast agent concentration can be calculated from T1 relaxation times using the known linear relationship [ 5]. The time course obtained can be characterized by the initial area under the contrast agent concentration-time curve (iAUC) or a pharmacokinetic model may be applied. With the latter, the data are fitted to estimate the transfer of contrast agent between the plasma and the extracellular, extravascular space (the transfer constant $\left.\mathrm{K}^{\text {trans }}\right)$. Although iAUC and $\mathrm{K}^{\text {trans }}$ are incompletely validated endpoints that are sensitive to changes in a number of hemodynamic parameters, including blood flow, blood volume, vessel permeability and vessel surface area [ 6], emerging data from several early-phase clinical trials of VEGF signaling inhibitors have shown changes in $\mathrm{K}$ trans and/or iAUC that are consistent with reductions in VEGF-dependent tumor perfusion and vascular permeability [ 7-11].

Vandetanib (ZACTIMA ${ }^{\mathrm{TM}}$ ) is a once-daily oral anticancer drug that selectively targets VEGFR-dependent tumor angiogenesis and REarranged during Transfection (RET)- and epidermal growth factor receptor (EGFR)-dependent tumor cell proliferation and survival. Preclinical DCE-MRI studies of vandetanib have demonstrated acute effects on hemodynamic variables in human prostate and colon xenograft models consistent with inhibition of VEGF signaling [ $12,13]$. Vandetanib is currently in phase III development in advanced non-small-cell lung cancer (NSCLC) and medullary thyroid cancer. Two doses of vandetanib were selected for investigation in the present study (100 mg and $300 \mathrm{mg}$ ). Previous phase I studies of vandetanib have shown these doses to be well tolerated and to achieve steadystate plasma levels that are likely to be biologically active [ 14-16]. In addition, both doses were clinically active as monotherapy in phase II studies in NSCLC [ 17] and medullary thyroid cancer [ 18, 19].

The primary objective of this open-label, randomized phase I study (study code D4200C00050) was to assess by DCEMRI the effect of once-daily vandetanib on $\mathrm{K}^{\text {trans }}$ and iAUC ${ }_{60}$ (iAUC of the first $60 \mathrm{~s}$ after contrast agent arrival) in patients with advanced colorectal cancer and liver metastases. An exploratory objective was to investigate the effects of vandetanib on the tumor by intrinsic susceptibility MRI, a technique that may have utility in measuring tumor hypoxia in response to vascular disruption [20].

\section{Methods}

\section{Patients}

Eligible patients were adults with histologically confirmed metastatic colorectal adenocarcinoma (stage IV) with at least one measurable hepatic lesion $\geq 20 \mathrm{~mm}$, WHO performance status $0-2$, life expectancy $\geq 12$ weeks, and no significant cardiac, hematopoietic, hepatic and renal dysfunction. Patients with brain metastases were eligible if treated at least 4 weeks before the start of study treatment and if clinically stable without steroid treatment for $\geq 10$ days. Key exclusion criteria were previous chemotherapy and/or radiotherapy (excluding palliative radiotherapy) less than 4 weeks before the start of study therapy, a QTc interval $\geq 480 \mathrm{~ms}$ during ECG screening, and poorly controlled hypertension. Patients for whom MRI scanning is contraindicated (e.g. pacemaker, heart valve replacement) were also excluded.

\section{Study design}

In this open-label study, 24 patients were planned to be randomized 1:1 to receive once-daily oral doses of vandetanib $100 \mathrm{mg}$ or $300 \mathrm{mg}$. There was no stratification and patients continued treatment until progressive disease, withdrawal due to toxicity, patient lost to follow up, severe non-compliance with the protocol or voluntary discontinuation by the patient. The primary objective of this study was to assess by DCE-MRI the effect of once-daily dosing with vandetanib on the tumor vasculature by determining iAUC $60^{\text {and }} \mathrm{K}^{\text {trans }}$. Secondary assessments included safety and tolerability, pharmacokinetics, and a preliminary evaluation of efficacy. Exploratory assessments included the effects of vandetanib on the tumor by intrinsic susceptibility MRI, measurement of the target tumor size by MRI, and the effect of vandetanib on soluble markers of angiogenesis.

The trial was approved by the Bundesinstitut für Arzneimittel und Medizinprodukte institutional review board/research ethics committee, and was conducted in accordance with the Declaration of Helsinki, Good Clinical Practice and the AstraZeneca policy on Bioethics. All patients provided written informed consent.

\section{Assessments}

\section{Statistical analyses}

The effect of vandetanib on MRI parameters was assessed using repeated measures analysis of variance (ANOVA) model fitted to $\log$ etransformed variables, with baseline as a covariate, dose and visit as fixed effects, and subjects as a random effect. Comparisons were performed to provide the least squares estimates and corresponding $95 \%$ CIs at each visit. Results are reported as the mean percentage change and associated 95\% CI from baseline by dose. The proportion of patients with a $>40 \%$ reduction post-baseline for $\mathrm{K}^{\text {trans }}$ and iAUC ${ }_{60}$ has been summarized for each dose 
level; the $>40 \%$ threshold was predefined and has been used previously for detection of anti-vascular activity by DCEMRI [ 7]. One-sided $P$ values were calculated for dose comparison of percentage decreases from baseline in $\mathrm{K}^{\text {trans }}$,

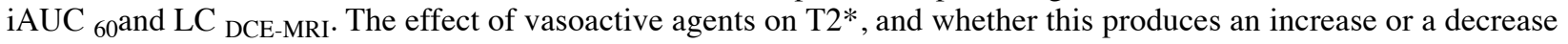
of $2^{*}$, depends on the balance between any change of blood volume and blood flow coupled with any change in oxygen utilization [ 25]. Since this effect could not be predicted in the present study, a two-sided $P$ value was calculated for $\mathrm{T} 2 *$. Population pharmacokinetic and pharmacokinetic-pharmacodynamic modeling was conducted using NONMEM software [ 26, 27].

\section{Results}

\section{Patients}

From 15 August 2006, 22 patients were enrolled in two centers in Germany and received study treatment; 10 patients were randomized to the vandetanib $100 \mathrm{mg}$ group and 12 patients to the vandetanib $300 \mathrm{mg}$ group (Table 1). The analysis population consisted of all subjects who had received at least one dose of vandetanib (intent-to-treat [ITT]). Eighteen patients continued study treatment until progression, three patients discontinued (two due to an adverse event, one due to violation of exclusion criteria) and one patient was ongoing on vandetanib $300 \mathrm{mg}$ at data cut-off (22 June 2007). Median exposure to vandetanib was 34 days (range 28-58) in the $100 \mathrm{mg}$ group and 60 days (range 9-202) in the $300 \mathrm{mg}$ group. The demographic characteristics and previous anticancer treatments were generally well balanced between the two cohorts, although there were more female patients in the vandetanib $300 \mathrm{mg}$ group than in the $100 \mathrm{mg}$ group.

Table 1

\begin{tabular}{l|c|c}
\hline Baseline characteristics & Vandetanib 100 $\mathbf{~ m g}(\boldsymbol{n}=\mathbf{1 0})$ & Vandetanib 300 mg $(\boldsymbol{n}=\mathbf{1 2})$ \\
\hline Median age, years (range) & $62.5(38--77)$ & $61(41--73)$ \\
Male $(\%)$ & $6(60)$ & $5(42)$ \\
Female $(\%)$ & $4(40)$ & $7(58)$ \\
Race & $10(100)$ & $12(100)$ \\
$\quad$ Caucasian (\%) & & \\
WHO performance status (\%) & $8(67) 4(33)$ \\
01 & $6(60) 4(40)$ & $12(100)$ \\
Previous chemotherapy regimens $(\%)$ & & $4(33)$ \\
Any & $10(100)$ & $2(17)$ \\
1 & $1(10)$ & $6(50)$ \\
2 & $3(30)$ & $7(58)$ \\
3 or more & $6(60)$ & $4(33)$ \\
Prior cetuximab therapy $(\%)$ & $7(70)$ & $5(50)$ \\
Prior bevacizumab therapy $(\%)$ & & \\
\hline
\end{tabular}

Patient characteristics (ITT population)

\section{MRI results}

\section{Pharmacokinetics}

After two doses of vandetanib, both the area under the curve to $24 \mathrm{~h}$ ( $\left.\mathrm{AUC}_{0-24}\right)$ and the maximum concentration (C max $)$ increased in a dose proportional manner, with gmean AUC $0-24$ of $1370 \mathrm{ng} / \mathrm{mL} \cdot \mathrm{h}(100 \mathrm{mg})$ and $4913 \mathrm{ng} / \mathrm{mL} \cdot \mathrm{h}(300$ $\mathrm{mg}$ ), and gmean $\mathrm{C}_{\text {max }}$ of $72.7 \mathrm{ng} / \mathrm{mL}(100 \mathrm{mg})$ and $268.5 \mathrm{ng} / \mathrm{mL}(300 \mathrm{mg})$. The gmean accumulation at steady state was 4.3 -fold in the $300 \mathrm{mg}$ group and 6.12-fold for the one evaluable patient in the $100 \mathrm{mg}$ dose group. Determination of $\mathrm{C}_{\text {min }}$ throughout the study period showed that steady-state exposure was achieved from day 15 onwards (Fig. 5 ). The fraction of vandetanib unbound on day 2 was approximately 0.065 for both doses and, based on the $300 \mathrm{mg}$ cohort, this was unaltered at the higher levels observed at steady state. A population pharmacokineticpharmacodynamic analysis showed little evidence of any correlation between the DCE-MRI variables and either the plasma concentration, daily exposure or total exposure to free or total vandetanib (data not shown).

\section{Figure 5}




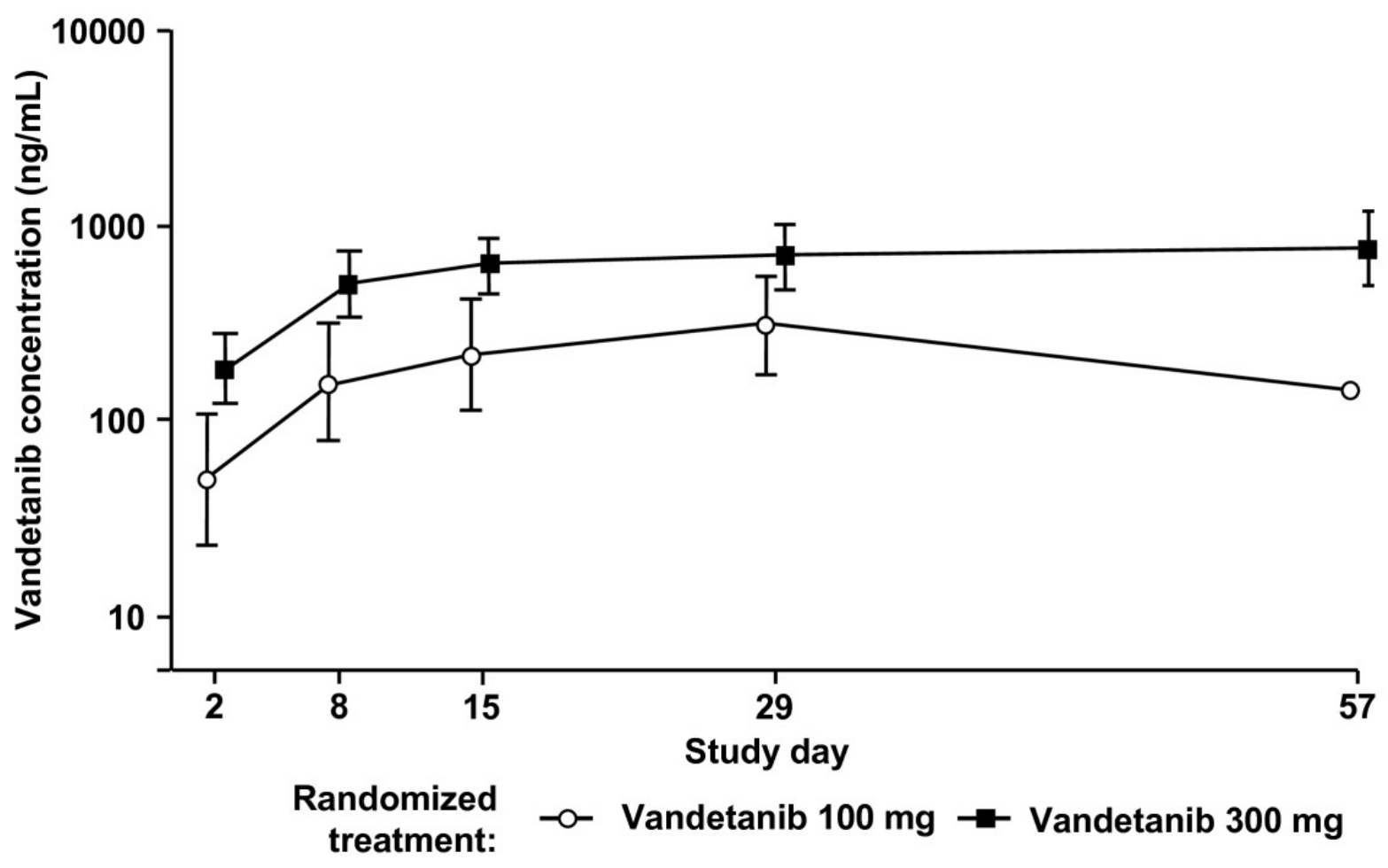

$\mathrm{C}_{\text {min }}$ plasma concentrations $(\mathrm{ng} / \mathrm{mL})$ for vandetanib $100 \mathrm{mg}$ and $300 \mathrm{mg}$. Data are shown as geometric mean ( \pm $\mathrm{SD})$.

\section{Soluble markers of angiogenesis/tumor activity}

Higher plasma levels of VEGF were detected at both vandetanib doses following multiple dosing, although large variability was observed (data not shown). There was no suggestion of a dose effect. No consistent time- or doserelated changes from baseline were observed for the other markers evaluated (sVEGFR-2, bFGF, EGFR, Tie-2, Ang1 and Ang2; data not shown).

\section{Efficacy}

There were no RECIST-defined objective responses as assessed by contrast-enhanced CT. Among the 21 evaluable patients, five patients in the $300 \mathrm{mg}$ group had a best response of stable disease $\geq 8$ weeks and the remaining 16 patients experienced progressive disease. One patient in the $300 \mathrm{mg}$ group had no post-baseline measurements and was therefore not evaluable. A waterfall plot of the best percentage change from baseline in the size of target lesions is presented in Fig. 6. Median PFS was 62 days (95\% CI, 57 to 177) in the $300 \mathrm{mg}$ group and 34 days (95\% CI, 33 to 37) in the $100 \mathrm{mg}$ group.

Figure 6 


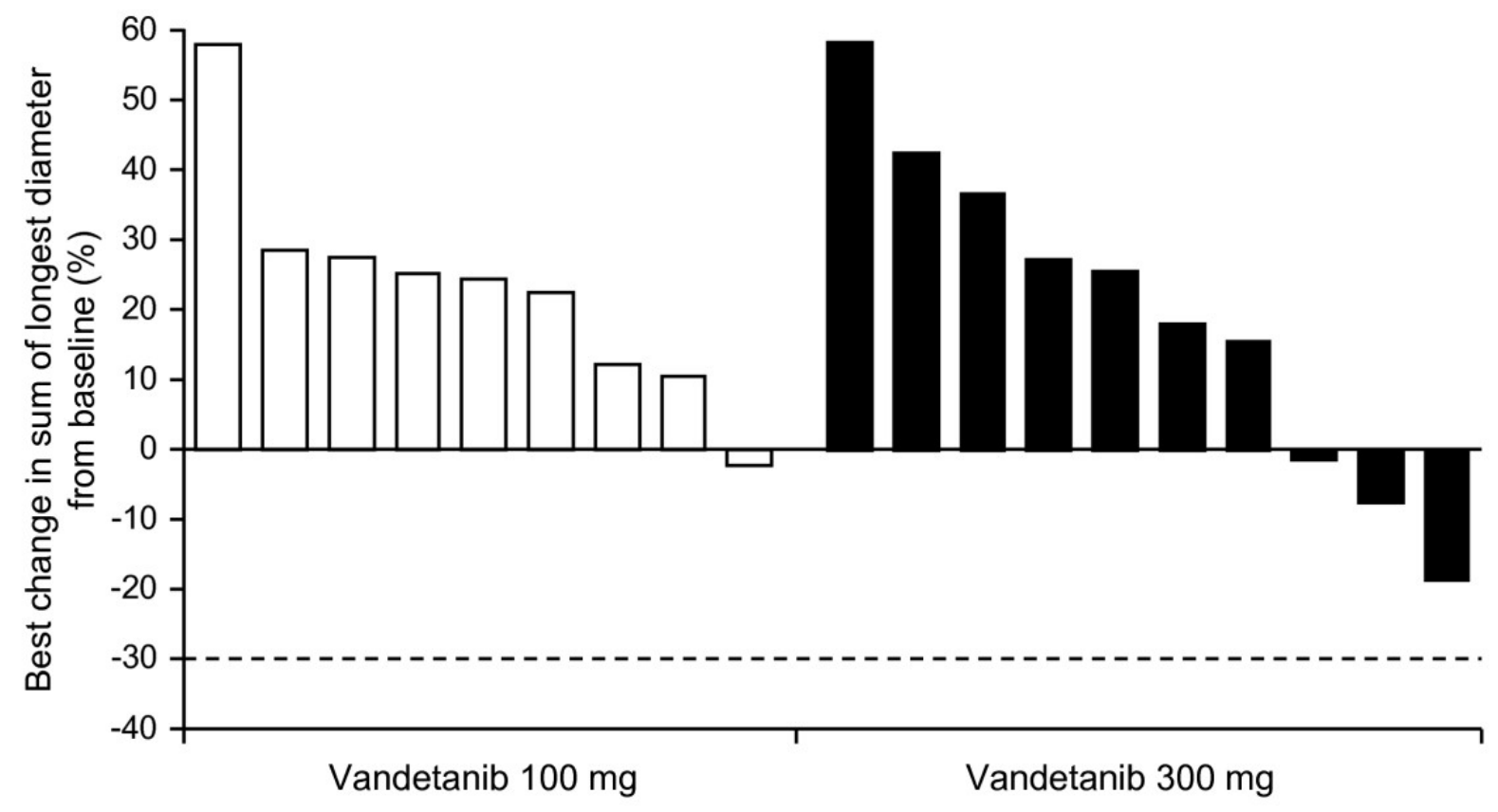

Best percentage change from baseline in the size of target lesion (RECIST assessment performed by CT). The best percentage change is defined as the biggest decrease, or smallest increase if no decrease. The threshold for partial response is $--30 \%$ (dashed line).

\section{Safety and tolerability}

Both vandetanib doses were generally well tolerated. The most frequently reported adverse events, irrespective of causality, were fatigue, diarrhea, dry mouth and nausea (Table 3). More adverse events were reported in the $300 \mathrm{mg}$ group compared with the $100 \mathrm{mg}$ group, which is consistent with the greater number of days on treatment for the 300 mg group. The majority of adverse events were CTCAE grade 1 or 2 , including all cases of diarrhea. The most common adverse events considered by the investigator to be related to vandetanib were dry mouth, dysphonia (both $n$ $=5)$, diarrhea, fatigue, acne, dry skin (all $n=4)$ and hypertension $(n=3)$. Four of these adverse events were CTCAE grade 3 (all $n=1$ ): allergic dermatitis, fatigue, photosensitivity reaction (all $300 \mathrm{mg}$ ) and hypertension (100 $\mathrm{mg}$ ). No grade 4 events were reported. Adverse events that were considered by the investigator to be related to study treatment were mostly manageable by dose reductions or interruptions. Two patients in the $300 \mathrm{mg}$ group experienced adverse events that led to discontinuation of treatment: allergic dermatitis and photosensitivity reaction (both grade 3 ) in one patient and QTc prolongation (grade 2) in another. Nine deaths occurred during this study before data cut-off and all were as a result of disease progression. Clinical laboratory evaluations did not show any clinically relevant changes in any clinical chemistry, hematology and urinalysis parameter. There was also no consistent trend in mean blood pressure values, although increases in systolic and/or diastolic blood pressure were observed during treatment, particularly in patients with a history of hypertension or patients who were borderline hypertensive at study entry. These increases in blood pressure were considered by the investigator to be related to vandetanib.

Table 3

\begin{tabular}{|c|c|c|c|}
\hline Adverse event* & $\begin{array}{c}\text { Vandetanib } 100 \mathrm{mg}(n=10) n \\
(\%)\end{array}$ & $\begin{array}{c}\text { Vandetanib } 300 \mathrm{mg}(n=12) n \\
(\%)\end{array}$ & 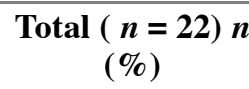 \\
\hline Fatigue & $6(60)$ & $7(58)$ & $13(59)$ \\
\hline $\operatorname{Rash}^{\dagger}$ & $2(20)$ & $10(83)$ & $11(50)$ \\
\hline Diarrhea & $2(20)$ & $7(58)$ & $9(41)$ \\
\hline Dry mouth & $2(20)$ & $4(33)$ & $6(27)$ \\
\hline Nausea & $3(30)$ & $3(25)$ & $6(27)$ \\
\hline Anorexia & $3(30)$ & $2(17)$ & $5(23)$ \\
\hline Dysphonia & $1(10)$ & $4(33)$ & $5(23)$ \\
\hline Abdominal pain & $1(10)$ & $3(25)$ & $4(18)$ \\
\hline Acne & 0 & $4(33)$ & $4(18)$ \\
\hline Cough & $1(10)$ & $3(25)$ & $4(18)$ \\
\hline Dizziness & $3(30)$ & $1(8)$ & $4(18)$ \\
\hline Dry skin & $1(10)$ & $3(25)$ & $4(18)$ \\
\hline Flatulence & $1(10)$ & $3(25)$ & $4(18)$ \\
\hline Hypertension & $1(10)$ & $3(25)$ & $4(18)$ \\
\hline
\end{tabular}




\begin{tabular}{l|c|c|c}
\hline Adverse event* & $\begin{array}{c}\text { Vandetanib 100 } \mathbf{~ m g}(\boldsymbol{n}=\mathbf{1 0}) \boldsymbol{n} \\
(\mathbf{\%})\end{array}$ & $\begin{array}{c}\text { Vandetanib 300 } \mathbf{~ m g}(\boldsymbol{n}=\mathbf{1 2}) \boldsymbol{n} \\
(\mathbf{\%})\end{array}$ & $\begin{array}{c}\text { Total }(\boldsymbol{n}=\mathbf{2 2}) \boldsymbol{n} \\
(\mathbf{\%})\end{array}$ \\
\hline Insomnia & $3(30)$ & $1(8)$ & $4(18)$ \\
$\begin{array}{l}\text { Nasopharyngitis } \\
\text { Peripheral }\end{array}$ & $2(20)$ & $2(17)$ & $4(18)$ \\
edema & $4(40)$ & 0 & $4(18)$ \\
$\begin{array}{l}\text { Sinus } \\
\text { tachycardia }\end{array}$ & $1(10)$ & $3(25)$ & $4(18)$ \\
$\begin{array}{l}\text { Weight } \\
\text { decreased }\end{array}$ & $1(10)$ & $3(25)$ & $4(18)$ \\
\hline
\end{tabular}

*MedDRA-preferred term except for rash

$\dagger$ MedDRA grouped term, which includes the following preferred terms: dry skin, erythema, photosensitivity reaction, rash papular, rash pustular, dermatitis allergic, exfoliative rash, and rash erythematous

Adverse events reported in $>3$ patients overall

\section{Discussion}

This randomized, open-label study used DCE-MRI to investigate the effect of once-daily oral dosing with vandetanib $(100 \mathrm{mg}$ or $300 \mathrm{mg})$ on tumor perfusion and vascular permeability in 22 patients with advanced colorectal cancer and liver metastases. The primary DCE-MRI variables of $\mathrm{iAUC}_{60}$ and $\mathrm{K}^{\text {trans }}$ did not show any statistically significant changes from baseline for either treatment group. Therefore, the study did not support the hypothesis that vandetanib has effects on tumor vasculature, as defined by changes in gadolinium uptake measured by iAUC 60 and $\mathrm{K}^{\text {trans }}$. The safety and pharmacokinetic profiles of vandetanib were similar to those observed in previous phase I studies [ 15, 16]. Both vandetanib doses were generally well tolerated with no new toxicities reported. A preliminary assessment of efficacy showed no RECIST objective responses in either treatment group, with five patients in the $300 \mathrm{mg}$ group experiencing a best response of stable disease.

There are several possible explanations for the absence of detectable changes in gadolinium uptake and tumor shrinkage with vandetanib in this setting. Although variations in institutional DCE-MRI protocols and different patient populations do not permit direct comparison, studies of other VEGFR-2 tyrosine kinase inhibitors have demonstrated reductions in iAUC/K $\mathrm{K}^{\text {trans }}$ in patients with advanced cancer [ 7-10]. Therefore, one explanation could be that vandetanib is not sufficiently active versus VEGFR-2 at the two doses investigated. However, this seems unlikely given that vandetanib has previously demonstrated single-agent antitumor activity at $100 \mathrm{mg}$ and $300 \mathrm{mg}$ in NSCLC [ 17] and in medullary thyroid cancer [ 18, 19]; the present study also showed some evidence of antitumor effects (though not tumor shrinkage), with five patients in the $300 \mathrm{mg}$ cohort experiencing stable disease. Inhibition of EGFR (NSCLC) and RET (medullary thyroid cancer) tyrosine kinases is also likely to be contributing to the activity of vandetanib in these tumor types; nevertheless, its relatively greater potency versus VEGFR-2 in vitro [ 14] suggests that vandetanib should achieve at least comparable inhibition of VEGFR-2 versus EGFR/RET in vivo . Moreover, in the present study, both vandetanib doses achieved steady-state plasma drug levels that were several-fold greater than the IC ${ }_{50}$ for inhibition of VEGF-dependent proliferation of human umbilical vein endothelial cells $(29 \mathrm{ng} / \mathrm{mL})$ [ 28]. An anti-VEGFR-2 effect of vandetanib at $100 \mathrm{mg}$ and $300 \mathrm{mg}$ is also supported by an exploratory pharmacodynamic study in patients with breast cancer, which showed inhibition of VEGFR-2 phosphorylation in skin biopsy tissue after 28 days of vandetanib treatment [29].

A second explanation may be that vandetanib is not active against the tumor vasculature in this particular disease setting. Indeed, the antitumor effects of vandetanib in this group of patients with colorectal cancer were modest compared with its single-agent activity in NSCLC [ 17] or medullary thyroid cancer [ 18, 19]. Furthermore, the canonical changes in plasma VEGF and VEGFR-2 that have been observed with vandetanib in NSCLC [17] and with other VEGFR tyrosine kinase inhibitors across different tumor types $[7,30]$ were not seen in the present study. In patients with colorectal cancer, objective tumor responses and effects on gadolinium uptake in tumor vasculature have been observed in single-agent studies of cediranib [ 7] and vatalanib [ 31]. Both of these VEGFR tyrosine kinase inhibitors, as well as bevacizumab, have activity versus VEGFR-1 and VEGFR-2 signaling [ 32, 33]. In contrast, vandetanib is selective for VEGFR-2 versus VEGFR-1 [28]. It is known that colorectal tumor cells express VEGFR-1 and that autocrine signaling may play a role in tumor cell survival/migration [34]. Activity versus VEGFR-1 may therefore be an important contribution to any effects of antiangiogenic agents on both RECIST assessments and gadolinium uptake in colorectal cancer. In this respect, it is interesting that a recent pan-tumor study with CDP791, a high affinity PEGylated di-Fab conjugate that specifically binds VEGFR-2, showed limited efficacy and no effect on K trans [35].

As discussed above, vandetanib has additional activity versus EGFR and the adverse event profile of vandetanib in this and previous studies [ $17,36,37$ ] is consistent with pharmacodynamic inhibition of both VEGFR (hypertension) and EGFR signaling (rash, diarrhea). Combining inhibition of VEGF (bevacizumab) and EGFR (cetuximab) signaling on a background of chemotherapy has been investigated in two recent colorectal cancer studies, which produced different outcomes. The exploratory efficacy results from the BOND-2 study in irinotecan-refractory, bevacizumab- and 
cetuximab-naïve patients suggested that adding bevacizumab to cetuximab \pm irinotecan may be more effective compared with historical controls [38]. However, the first-line CAIRO-2 study found that adding cetuximab to bevacizumab, capecitabine and oxaliplatin resulted in a significantly shorter PFS [ 39]. The CAIRO-2 authors speculated that these results may be due to a negative interaction between cetuximab and bevacizumab, and noted that the incidence of hypertension, a relatively common side effect of treatment with bevacizumab and other VEGF signaling inhibitors, was significantly reduced in patients receiving cetuximab. These data suggest, at least in some settings, that the vascular effects associated with VEGF inhibition may be diminished with concomitant EGFR inhibition. Other than vandetanib, AEE788 is the only dual VEGFR and EGFR tyrosine kinase inhibitor in clinical development and it is worth noting that AEE788 also showed no effect on gadolinium uptake in patients with advanced colorectal cancer and liver metastases [ 40]. An additional factor in the present study is that most patients had received previous treatment with bevacizumab and/or cetuximab, which may have affected responsiveness to subsequent VEGFR-2/EGFR tyrosine kinase inhibition. The mechanism of tumor resistance to the monoclonal antibodies bevacizumab and cetuximab is not well understood and warrants further investigation.

It is also possible that vandetanib treatment may induce hemodynamic changes, such as normalization/remodeling of the tumor vasculature as hypothesized by Jain [ 41], that would not necessarily be detected by estimating changes in $\mathrm{K}$ trans and iAUC 60. More complex DCE-MRI approaches such as the St Lawrence and Lee model [ 42], which is able to derive independent measurement of blood flow, blood volume and permeability surface area, may be more appropriate for detecting complex changes in tumor vascularity and hemodynamics. Normalization of the tumor vasculature might also be expected to improve tumor oxygenation and blood flow. In this regard, the results from the exploratory assessment of $\mathrm{T}^{*}$ using intrinsic susceptibility MRI merit discussion. Changes in $\mathrm{T} 2 *$ can be used to monitor changes in deoxyhemoglobin and an increase in T2* could result from improved tumor oxygenation and blood flow (i.e., normalization) [ 25]. However, T2* is influenced by other factors and is therefore a difficult parameter to interpret on its own [ 25, 43]. In the absence of detectable effects on tumor hemodynamics as measured by DCE-MRI, an increase in $\mathrm{T} 2 *$ could be attributed to an increase in tumor cell death [ 43,44$]$. As such, the significant increase in T2* at vandetanib $300 \mathrm{mg}$ compared with $100 \mathrm{mg}$ in the present study may reflect increased tumor necrosis at the higher dose. Further correlative work is needed to understand the biological basis of changes in $\mathrm{T} 2 *$ in the clinical setting.

Population pharmacokinetic-pharmacodynamic analyses showed no correlation between vandetanib exposure and any of the pharmacodynamic parameters analyzed. Given the long half-life of vandetanib, it may take up to 4 weeks for vandetanib to reach steady state [14]; in the present study, steady state was attained from day 15 at the earliest, but was mostly from day 22 onwards. It is not fully understood how tumor growth/adaptation during this prolonged period of drug accumulation may affect pharmacodynamic variables.

\section{Conclusion}

In the present study, DCE-MRI assessments of iAUC ${ }_{60}$ and $\mathrm{K}^{\text {trans }}$ provided no evidence that vandetanib modulated gadolinium uptake within the tumor vasculature of patients with advanced colorectal cancer and liver metastases. As discussed, these findings from a small open-label study of only 24 patients should be interpreted with caution, particularly since vandetanib has previously demonstrated evidence of antitumor activity in phase II studies in advanced NSCLC and medullary thyroid cancer that is consistent with inhibition of VEGFR activity. Vandetanib is one of a number of VEGF signaling inhibitors in clinical development and each has a different pharmacological profile [ 45]. We raise the possibility that the different selectivity profiles could result in agent-specific pharmacodynamic effects on tumor vasculature that may not be completely accounted for by changes in DCE-MRI variables such as ${ }_{\text {iAUC }}{ }_{60}$ and $\mathrm{K}^{\text {trans }}$. Vandetanib continues to be investigated in a range of other tumor types, including colorectal cancer and phase III programs in advanced NSCLC and medullary thyroid cancer.

\section{Declarations}

\section{Acknowledgements}

We thank John Matthew of Mudskipper Bioscience who provided medical writing support funded by AstraZeneca.

\section{Authors' original submitted files for images}

Below are the links to the authors' original submitted files for images.

Authors' original file for figure 1

Authors' original file for figure 2

Authors' original file for figure 3

Authors' original file for figure 4

Authors' original file for figure 5

Authors' original file for figure 6 


\section{Competing interests}

TPM, JT, ADK and AJR are all full-time employees of AstraZeneca. The authors declare no other competing interests.

\section{Authors' contributions}

All authors contributed to the design of the study or manuscript writing, and have read and approved the final manuscript.

\section{References}

1. Hurwitz H, Fehrenbacher L, Novotny W, Cartwright T, Hainsworth J, Heim W, Berlin J, Baron A, Griffing S, Holmgren E, Ferrara N, Fyfe G, Rogers B, Ross R, Kabbinavar F. Bevacizumab plus irinotecan, fluorouracil, and leucovorin for metastatic colorectal cancer. N Engl J Med. 2004;350:2335-2342.

View Article Google Scholar

2. Sandler A, Gray R, Perry MC, Brahmer J, Schiller JH, Dowlati A, Lilenbaum R, Johnson DH. Paclitaxelcarboplatin alone or with bevacizumab for non-small-cell lung cancer. N Engl J Med. 2006;355:25422550 .

View Article Google Scholar

3. Motzer RJ, Hutson TE, Tomczak P, Michaelson MD, Bukowski RM, Rixe O, Oudard S, Negrier S, Szczylik C, Kim ST, Chen I, Bycott PW, Baum CM, Figlin RA. Sunitinib versus interferon alfa in metastatic renal-cell carcinoma. N Engl J Med. 2007;356:115-124.

View Article Google Scholar

4. Escudier B, Eisen T, Stadler WM, Szczylik C, Oudard S, Siebels M, Negrier S, Chevreau C, Solska E, Desai AA, Rolland F, Demkow T, Hutson TE, Gore M, Freeman S, Schwartz B, Shan M, Simantov R, Bukowski RM. Sorafenib in advanced clear-cell renal-cell carcinoma. N Engl J Med. 2007;356:125-134. View Article Google Scholar

5. Rohrer M, Bauer H, Mintorovitch J, Requardt M, Weinmann HJ. Comparison of magnetic properties of MRI contrast media solutions at different magnetic field strengths. Invest Radiol. 2005;40:715-724.

View Article Google Scholar

6. O'Connor JP Jackson A Parker GJ Jayson GC DCE-MRI biomarkers in the clinical evaluation of antiangiogenic and vascular disrupting agents Br J Cancer 2007961891952359994 $10.1038 /$ sj.bjc. 6603515

7. Drevs J, Siegert P, Medinger M, Mross K, Strecker R, Zirrgiebel U, Harder J, Blum H, Robertson J, Jürgensmeier JM, Puchalski TA, Young H, Saunders O, Unger C. Phase I clinical study of AZD an oral vascular endothelial growth factor signaling inhibitor, in patients with advanced solid tumors. J Clin Oncol. 2007;25:3045-3054.

View Article Google Scholar

8. Liu G, Rugo HS, Wilding G, McShane TM, Evelhoch JL, Ng C, Jackson E, Kelcz F, Yeh BM, Lee FT, Charnsangavej C, Park JW, Ashton EA, Steinfeldt HM, Pithavala YK, Reich SD, Herbst RS. Dynamic contrast-enhanced magnetic resonance imaging as a pharmacodynamic measure of response after acute dosing of AG-01 an oral angiogenesis inhibitor, in patients with advanced solid tumors: results from a Phase I study. J Clin Oncol. 2005;23:5464-5473.

View Article Google Scholar

9. Mross K, Drevs J, Muller M, Medinger M, Marme D, Hennig J, Morgan B, Lebwohl D, Masson E, Ho YY, Gunther C, Laurent D, Unger C. Phase I clinical and pharmacokinetic study of PTK/ZK, a multiple VEGF receptor inhibitor, in patients with liver metastases from solid tumours. Eur J Cancer. 2005;41:1291-1299.

View Article Google Scholar

10. Mross K, Gmehling D, Frost A, Baas F, Strecker R, Hennig J, Stopfer P, Stefanic M, Stehle G, de Rossi L. . A clinical phase I, pharmacokinetic (PK), and pharmacodynamic study of twice daily BIBF 1120 in advanced cancer patients. 2005;:-

View Article Google Scholar 
11. Wedam SB, Low JA, Yang SX, Chow CK, Choyke P, Danforth D, Hewitt SM, Berman A, Steinberg SM, Liewehr DJ, Plehn J, Doshi A, Thomasson D, McCarthy N, Koeppen H, Sherman M, Zujewski J, Camphausen K, Chen H, Swain SM. Antiangiogenic and antitumor effects of bevacizumab in patients with inflammatory and locally advanced breast cancer. J Clin Oncol. 2006;24:769-777.

View Article Google Scholar

12. Bradley DP, Tessier JL, Checkley D, Kuribayashi H, Waterton JC, Kendrew J, Wedge SR. Effects of AZD2171 and vandetanib (ZD Zactima) on haemodynamic variables in an SW620 human colon tumour model: an investigation using dynamic contrast-enhanced MRI and the rapid clearance blood pool contrast agent, P792 (gadomelitol). NMR Biomed. 2007;21:42-52.

View Article $\underline{\text { Google Scholar }}$

13. Checkley D Tessier JJ Kendrew J Waterton JC Wedge SR Use of dynamic contrast-enhanced MRI to evaluate acute treatment with ZD a VEGF signalling inhibitor, in PC-3 prostate tumours Br J Cancer 200389188918952394431 10.1038/sj.bjc.6601386

14. Herbst RS, Heymach JV, O'Reilly MS, Onn A, Ryan AJ. Vandetanib (ZD6474): an orally available receptor tyrosine kinase inhibitor that selectively targets pathways critical for tumor growth and angiogenesis. Expert Opin Investig Drugs. 2007;16:239-249.

View Article Google Scholar

15. Holden SN, Eckhardt SG, Basser R, de Boer R, Rischin D, Green M, Rosenthal MA, Wheeler C, Barge A, Hurwitz HI. Clinical evaluation of ZD an orally active inhibitor of VEGF and EGF receptor signaling, in patients with solid, malignant tumors. Ann Oncol. 2005;16:1391-1397.

View Article Google Scholar

16. Tamura T, Minami H, Yamada Y, Yamamoto N, Shimoyama T, Murakami H, Horiike A, Fujisaka Y, Shinkai S, Tahara M, Kawada K, Ebi H, Sasaki Y, Jiang H, Saijo N. A Phase I dose-escalation study of ZD6474 in Japanese patients with solid, malignant tumors. J Thorac Oncol. 2006;1:1002-1009.

View Article Google Scholar

17. Kiura K, Nakagawa K, Shinkai T, Eguchi K, Ohe Y, Yamamoto N, Tsuboi M, Yokota S, Seto T, Jiang H, Nishio K, Saijo N, Fukuoka M. A randomized, double-blind, phase IIa dose-finding study of Vandetanib (ZD6474) in Japanese patients with non-small cell lung cancer. J Thorac Oncol. 2008;3:386-393. View Article Google Scholar

18. Haddad RI, Krebs AD, Vasselli J, Paz-Ares LG, Robinson B. . A phase II open-label study of vandetanib in patients with locally advanced or metastatic hereditary medullary thyroid cancer. 2008;:- .

View Article Google Scholar

19. Wells SA, Gosnell JE, Gagel RF, Moley JF, Pfister DG, Sosa JA, Skinner M, Krebs A, Hou J, Schlumberger M. . Vandetanib in metastatic hereditary medullary thyroid cancer: Follow-up results of an open-label phase II trial. $2007 ;:-$.

View Article Google Scholar

20. Bradley DP Tessier JJ Ashton SE Waterton JC Wilson Z Worthington PL Ryan AJ Correlation of MRI biomarkers with tumor necrosis in Hras5 tumor xenograft in athymic rats Neoplasia 20079382 3911877977 10.1593/neo.07145

21. Scheffler K, Hennig J. T(1) quantification with inversion recovery TrueFISP. Magn Reson Med. 2001;45:720-723.

View Article Google Scholar

22. Scheffler K. On the transient phase of balanced SSFP sequences. Magn Reson Med. 2003;49:781-783. View Article Google Scholar

23. Tofts PS. Modeling tracer kinetics in dynamic Gd-DTPA MR imaging. J Magn Reson Imaging. 1997;7:91101.

View Article Google Scholar

24. Evelhoch JL, LoRusso PM, He Z, DelProposto Z, Polin L, Corbett TH, Langmuir P, Wheeler C, Stone A, Leadbetter J, Ryan AJ, Blakey DC, Waterton JC. Magnetic resonance imaging measurements of the response of murine and human tumors to the vascular-targeting agent ZD6126. Clin Cancer Res. 2004;10:3650-3657. 
25. Howe FA, Robinson SP, McIntyre DJ, Stubbs M, Griffiths JR. Issues in flow and oxygenation dependent contrast (FLOOD) imaging of tumours. NMR Biomed. 2001;14:497-506.

View Article Google Scholar

26. Beal SL, Sheiner LB. Estimating population kinetics. Crit Rev Biomed Eng. 1982;8:195-222. View Article Google Scholar

27. Mandema JW, Verotta D, Sheiner LB. Building population pharmacokinetic--pharmacodynamic models. I. Models for covariate effects. J Pharmacokinet Biopharm. 1992;20:511-528.

View Article Google Scholar

28. Wedge SR, Ogilvie DJ, Dukes M, Kendrew J, Chester R, Jackson JA, Boffey SJ, Valentine PJ, Curwen JO, Musgrove HL, Graham GA, Hughes GD, Thomas AP, Stokes ES, Curry B, Richmond GH, Wadsworth PF, Bigley AL, Hennequin LF. ZD6474 inhibits vascular endothelial growth factor signaling, angiogenesis, and tumor growth following oral administration. Cancer Res. 2002;62:4645-4655.

View Article Google Scholar

29. Baselga J, Trigo JM, Rojo F, Ryan AJ, Wheeler C, Barge A, Sledge GW, Miller KD. Pharmacodynamic assessment of ZD6474 (ZACTIMA ${ }^{\mathrm{TM}}$ ) in the skin of patients with previously treated metastatic breast cancer. Clin Cancer Res. $2005 ;:-$.

View Article Google Scholar

30. Motzer RJ, Michaelson MD, Redman BG, Hudes GR, Wilding G, Figlin RA, Ginsberg MS, Kim ST, Baum CM, DePrimo SE, Li JZ, Bello CL, Theuer CP, George DJ, Rini BI. Activity of SU1 a multitargeted inhibitor of vascular endothelial growth factor receptor and platelet-derived growth factor receptor, in patients with metastatic renal cell carcinoma. J Clin Oncol. 2006;24:16-24.

View Article Google Scholar

31. Thomas AL, Morgan B, Horsfield MA, Higginson A, Kay A, Lee L, Masson E, Puccio-Pick M, Laurent D, Steward WP. Phase I study of the safety, tolerability, pharmacokinetics, and pharmacodynamics of PTK787/ZK 222584 administered twice daily in patients with advanced cancer. J Clin Oncol. 2005;23:4162-4171.

View Article Google Scholar

32. Ferrara N, Hillan KJ, Gerber HP, Novotny W. Discovery and development of bevacizumab, an anti-VEGF antibody for treating cancer. Nat Rev Drug Discov. 2004;3:391-400.

View Article Google Scholar

33. Lee D, Heymach JV. Emerging antiangiogenic agents in lung cancer. Clin Lung Cancer. 2006;7:304-308. View Article Google Scholar

34. Fan F, Wey JS, McCarty MF, Belcheva A, Liu W, Bauer TW, Somcio RJ, Wu Y, Hooper A, Hicklin DJ, Ellis LM. Expression and function of vascular endothelial growth factor receptor-1 on human colorectal cancer cells. Oncogene. 2005;24:2647-2653.

View Article Google Scholar

35. Ton NC, Parker GJM, Jackson A, Mullamitha S, Buonaccorsi GA, Roberts C, Watson Y, Davies K, Cheung S, Hope L, Power F, Lawrance J, Valle J, Saunders M, Felix R, Soranson JA, Rolfe L, Zinkewich-Peotti K, Jayson GC. Phase I Evaluation of CDP791, a PEGylated Di-Fab' Conjugate that Binds Vascular Endothelial Growth Factor Receptor 2. Clin Cancer Res. 2007;13:7113-7118.

View Article Google Scholar

36. Heymach JV, Paz-Ares L, de Braud F, Sebastian M, Stewart DJ, Eberhardt WE, Ranade A, Cohen G, Trigo JM, Sandler AB, Bonomi PD, Herbst RS, Krebs AD, Vasselli J, Johnson BE. Randomized phase II study of vandetanib alone or with paclitaxel and carboplatin as first-line treatment for advanced non-small-cell lung cancer. J Clin Oncol. 2008;26:5407-5415.

View Article Google Scholar

37. Heymach JV, Johnson BE, Prager D, Csada E, Roubec J, Pesek M, Spasova I, Belani CP, Bodrogi I, Gadgeel S, Kennedy SJ, Hou J, Herbst RS. Randomized, placebo-controlled phase II study of vandetanib plus docetaxel in previously treated non-small-cell lung cancer. J Clin Oncol. 2007;25:4270-4277. 
38. Saltz LB, Lenz HJ, Kindler HL, Hochster HS, Wadler S, Hoff PM, Kemeny NE, Hollywood EM, Gonen M, Quinones M, Morse M, Chen HX. Randomized phase II trial of cetuximab, bevacizumab, and irinotecan compared with cetuximab and bevacizumab alone in irinotecan-refractory colorectal cancer: the BOND-2 study. J Clin Oncol. 2007;25:4557-4561.

View Article Google Scholar

39. Tol J, Koopman M, Cats A, Rodenburg CJ, Creemers GJM, Schrama JG, Erdkamp FLG, Vos AH, Van Groeningen CJ, Sinnige HAM, Richel DJ, Voest EE, Dijkstra JR, Vink-Borger ME, Antonini NF, Mol L, van Krieken JHJM, Dalesio O, Punt CJA. Chemotherapy, Bevacizumab, and Cetuximab in Metastatic Colorectal Cancer. N Engl J Med. 2009;360:563-572.

View Article Google Scholar

40. Xiong HQ, Takimoto C, Rojo F, Davis D, Huang J, Abbruzzese JL, Dugan M, Thomas A, Mita A, Steward WP. . A phase I study of AEE788, a multitargeted inhibitor of ErbB and VEGF receptor family tyrosine kinases, to determine safety, PK and PD in patients (pts) with advanced colorectal cancer (CRC) and liver metastases. $2007 ;:-$.

View Article Google Scholar

41. Jain RK. Normalization of tumor vasculature: an emerging concept in antiangiogenic therapy. Science. 2005;307:58-62.

View Article Google Scholar

42. Lee TY, Purdie TG, Stewart E. CT imaging of angiogenesis. Q J Nucl Med. 2003;47:171-187. View Article Google Scholar

43. Robinson SP Kalber TL Howe FA McIntyre DJ Griffiths JR Blakey DC Whittaker L Ryan AJ Waterton JC Acute tumor response to ZD6126 assessed by intrinsic susceptibility magnetic resonance imaging Neoplasia 200574664741501158 10.1593/neo.04622

44. Padhani AR. MRI for assessing antivascular cancer treatments. Br J Radiol. 2003;76:S60-S80. View Article Google Scholar

45. Wedge SR, Jurgensmeier JM. Vascular endothelial growth factor receptor tyrosine kinase inhibitors for the treatment of cancer. Tumor Angiogenesis: Basic Mechanisms and Cancer Therapy. 2008;:395-424. View Article Google Scholar 